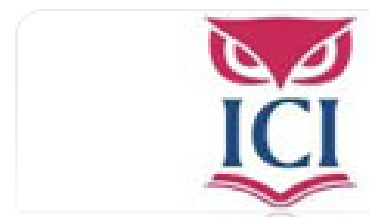

IUS. Revista del Instituto de Ciencias Jurídicas de Puebla A.C.

ISSN: 1870-2147

revista.ius@hotmail.com

Instituto de Ciencias Jurídicas de Puebla A. C.

México

Maffesoli, Michel

Apuntes sobre la actualidad

IUS. Revista del Instituto de Ciencias Jurídicas de Puebla A.C., núm. 19, 2007, pp. 200-204 Instituto de Ciencias Jurídicas de Puebla A. C.

Puebla, México 
ESTANTERÍA

En abril de 2006 la Universidad de las Américas creó la Cátedra Michel Maffesoli. Este texto es una de las conferencias que el autor de La tajada del diablo expuso en el marco de su instauración.

Reproducido de Posmodernidad, libro de reciente aparición de Michel Maffesoli, Universidad de las Américas Puebla, México, 2007.

\section{Apuntes sobre la actualidad}

Michel Maffesoli

Voy a compartirles mis líneas actuales de trabajo. Imparto un seminario de doctorado cuyo tema cambia cada dos años, el actual es sobre lo erótico-social. Retomé un tema que había tratado en un libro en 1982, La sombra de Dionisio, subtitulado Introducción a la sociología de la orgía. La orgía, en el sentido nietzscheano, no es lo relacionado con el orgasmo, sino más bien con la pasión. Lo que me interesaba en aquel entonces era cómo tomar en cuenta el estudio de la pasión colectiva. Veinticinco años después, retomo el asunto de la pasión colectiva de una manera mucho más amplia, esta vez introduzco el ángulo de lo eróticosocial. Para ello me apoyo en la fundamentación teórica del sociólogo alemán Max Scheler, quien escribió sobre una serie de cuestiones relacionadas con ardo amoris: el orden del amor. Me interesa la idea de que hay un orden, una lógica interna en la vida social.

El amor, lo erótico, no solamente es externo, nebuloso, es algo que comparte una lógica. Intento ver cómo en lo que llaman posmodernidad hay una lógica amorosa: la importancia del sentimiento, la importancia de las pasiones compartidas. Lo digo por medio de ejemplos muy sencillos para ver cómo las formas de lo político son totalmente marginadas: en un partido de futbol hay una congregación, un agrupamiento, y hay, en ese caso, una forma de histeria colectiva que predomina sobre cualquier otra cosa. Por ejemplo, cuando Francia ganó la copa del mundial de futbol, el mismo día hubo en Argelia una masacre de doscientas personas. Nadie habló de la masacre, el problema era esta histeria deportiva, para mí eso es lo erótico-social. Tomo este ejemplo, pero hay muchísimos más. Podemos remontarnos a un análisis de Durkheim, en su libro Las formas elementales de la vida religiosa, que es para mí uno de los grandes clásicos de la sociología. Durkheim analiza una fiesta de tribus australianas y trabaja sobre este tema tomando en cuenta otros trabajos de etnólogos. El análisis es muy sencillo, las tribus están esparcidas en el territorio de su vida cotidiana, pero de vez en cuando, "misteriosamente" -la expresión de Durkheim es muy interesante- se congregan. 
En ese momento desarrollan uno de sus signos importantes: la "efervescencia”. Correlativamente a este concepto de efervescencia está el concepto de anomia. Muestra cómo durante estas agregaciones festivas se da la transgresión sexual, la violencia ritualizada y la ingestión de drogas o productos tóxicos, de todo lo que es anómico. Haciendo énfasis sobre el término "anomia”, el ansia transgresiva no es en contra de la ley, sino más allá de la ley. Muestra cómo durante estos momentos anómicos - la frase es muy fuerte- la comunidad fortalece el sentimiento que tiene de sí misma. Se constituye como comunidad a partir de la anomia. Puesto que la tensión no se puede dilatar por mucho tiempo, las tribus regresan a su propio territorio y a la vida cotidiana hasta que en un momento dado, misteriosamente, tienen el deseo de regresar a congregarse. Para mí este momento de efervescencia es una anomia ritualizada. La violencia es ritualizada, el sexo colectivo también es ritualizado, la droga es ritualizada. Es lo que yo llamo una "homeopatización del mal”, una forma de vivir la cotidianidad. La efervescencia es como recargar una batería eléctrica. Vamos a vivir a partir de esta energía hasta que se necesite otra vez recargar y recrear esta energía. Ese ejemplo traduce muy bien para mí lo que es lo erótico-social en ciertos momentos, hay que encontrar elementos para pensar este binomio que, desde mi punto de vista, se seguirá desarrollando en nuestras sociedades posmodernas y en las generaciones jóvenes. Las generaciones de nuestros estudiantes se van a fundamentar cada vez más sobre estos valores anómicos. Es mejor reconocerlo para acompañar el proceso, ritualizarlo y así evitar que se vuelva dañino. Acompañar, más que negar, aceptarlo como algo que ya estaba ahí. Esta idea, que es casi una ley social, la voy a formular de la siguiente manera: lo anómico de hoy es lo canónico de mañana.

Cuando observamos la historia de la humanidad vemos siempre este proceso. Podemos ver que todos los autores anómicos del fin del siglo XIX en literatura, pintura, música, en todos los terrenos, son ahora la referencia académica actual. Trabajo este tema, retorno veinticinco años de mi experiencia sobre esta pasión común e intento ver cómo hay una lógica en ello. Vuelvo a la idea de Michel Foucault de que hay una episteme. En ese sentido, entramos en una nueva episteme que, en la perspectiva de Foucault, es al mismo tiempo una manera de que se represente el mundo y de organizar el mundo con base en esta representación. Hay una idea lógica entre las formas de representación y, en el sentido sencillo de la palabra, las formas de organización: es la vigencia de la episteme, al contrario de la teoría pura. En cada uno de 
los dos casos se trata de un conocimiento, pero en el de la episteme se trata de un conocimiento práctico, un conocimiento que se encarna.

Cuando miramos la larga duración de la historia del pensamiento siempre hay una relación entre lo esotérico y lo exotérico, el sabio y la publicidad. Considero que ambos son necesarios, pero creo que se debe guardar una relación entre lo esotérico y lo exotérico. Con mayor precisión: lo exotérico solamente tiene sentido si se apoya y se arraiga sobre una investigación más seria, es decir, esotérica. El problema que veo en Europa y en Francia en particular, aunque no conozco suficientemente México, es que lo exotérico termina siendo suficiente para sí mismo y corta sus raíces con la investigación seria. Ahí sí hay un verdadero problema: los medios de comunicación sólo hablan de lo que entienden. Lo digo de una manera coloquial, con un refrán, "el burro que se rasca busca a otro burro". De cierta manera hay una convivencia, un verdadero problema que crea un pensamiento desencarnado.

Me molesta un poco hablar de Durkheim porque en la Sorbona yo tengo la cátedra de Durkheim. Cuando me nombraron fue una paradoja absoluta, bastante gente se dio cuenta porque mi formación, mi trasfondo era más bien de tendencia weberiana, pero trabajo bastante a Durkheim. Para la última edición de Las formas elementales de la vida religiosa redacté un prefacio. Hay que saber que Durkheim tenía como objetivo teórico "sociologizar" la filosofía cartesiana, y lo dice de manera explícita. Pensaba: lo que Descartes hizo en filosofía - pensar al sujeto racional, pensar al individuo crítico- yo lo voy a hacer pero desde un punto de vista sociológico; quiero demostrar cómo lo social solamente es la suma de individuos racionales; un poco como Descartes pensó el cogito ergo sum, yo voy a pensar a este sujeto que se asocia en forma contractual con otros sujetos. Desde este punto de vista, Durkheim representa el cumplimiento del pensamiento moderno y es, efectivamente, el fin de la modernidad desde una perspectiva que se fundamenta bien sobre esa idea de lo social.

Lo social, como ustedes saben, es una invención del siglo XIX. ¿Qué es lo social? Cuando en Japón, a principios del siglo $\mathrm{xx}$, se requirió traducir a los sociólogos, no había palabra para traducir "social". Se requerían perífrasis. Insisto sobre este punto para dar a entender que eso es lo social, nominalmente.

Yo tengo muchos colegas mexicanos, pero desconozco cuál es el debate en México. En lo relacionado con el debate intelectual en Europa, nos quedamos en esta vieja idea de lo social elaborada al final del siglo XIX y principios del xx. Tanto en la izquierda como en la derecha hay una especie de equivalencia 
para pensar el aspecto contractual de individuos racionales. Por eso digo que Durkheim es la punta de lanza del pensamiento moderno. En varios de sus libros desarrolla dos conceptos o expresiones: la idea de la solidaridad mecánica y la idea de la solidaridad orgánica, mostrando que las sociedades primitivas se fundamentan en la solidaridad mecánica y la sociedad moderna sobre la orgánica. Yo propuse invertir los términos guardando las palabras de Durkheim, demostrar que en el fondo la solidaridad orgánica caracterizaba a las sociedades primitivas y la mecánica a las modernas. Mecánico, en el sentido sencillo de la palabra -lo podemos decir de una manera racionalista-, es que a partir de una causa se engendra un efecto. En el fondo la solidaridad mecánica es lo que hace que yo haga "eso", y "eso", tiene determinada consecuencia. ¿Por qué explico? Para decir que podemos recurrir a ciertos términos de Durkheim pero invirtiéndolos, poniéndolos al revés. En mi lectura de Durkheim entiendo que era un hombre de su tiempo, un pequeño burgués nacionalista, socialista, muy generoso, muy racionalista, y que solamente podía pensar por medio de "sus" categorías. Sin embargo, en particular lo que cité, hace que en Las formas elementales de la vida religiosa haya intuiciones que nos permiten entender muchísimos fenómenos de la posmodernidad, pero separándo- los del contexto de la doxa, es decir, de la opinión sabia, opinión en la cual él estaba metido. Voy a dar un ejemplo en relación con lo que decía hace rato. Las famosas fiestas y sus efervescencias pueden perfectamente aplicarse a todos estos agrupamientos deportivos, musicales, religiosos, consumistas, etcétera, en los cuales existen también los mismos procesos de efervescencia. Desde mi punto de vista sí se pueden utilizar los términos pero cambiando los vértices. Desde un punto de vista epistemológico, hay un concepto heideggeriano que podría explicar lo que estoy haciendo, no sé cómo está traducido al español pero tenemos muchos problemas para traducirlo en francés. Se traduce como retomar y distorsionar o torcer. En el fondo retomamos, pero al mismo tiempo les aplicamos una torción para que puedan ser útiles, no de una manera general para un pensamiento eterno, sino para ser aplicables a la realidad contemporánea. Ésa es mi manera de usar y abusar de Durkheim.

En un tiempo muy parecido al nuestro, durante el siglo XVIII o XIX, mientras ocurría una guerra de la mutación de los valores, Goethe decía que las civilizaciones son paradójicas en su nacimiento. Yo también pienso que en este momento hay paradojas. Por un lado, hay algo del orden de la mundialización y al mismo tiempo hay una reafirmación muy fuerte, hasta forzosa, de 
ESTANTERÍA

los particularismos. La imagen que he dado - una imagen mucho más seria aunque parezca frívola - es la mcdonalización, pero es al mismo tiempo el cassoulet (que es una especialidad de Toulouse). El cassoulet es importante porque es un platillo a la manera de lo que decía Marcel Mauss: la cocina como hecho social total. Eso es McDonalds. Para mí la posmodernidad es el lado paradójico, es una metáfora. Hay que ver posteriormente cómo se vive la paradoja. Por otro lado, hay que considerar la fragilidad de un imperio único, en particular el imperialismo de los Estados Unidos, con su característica particular: quieren imponer democracia donde no hay democracia. Pero junto a este imperialismo único y dominante me parece que hay indicios y ensayos del nacimiento de otros imperios. Regresa, ciertamente, la idea imperial, un término casi de ciencia política. Ésta es una hipótesis, es mi hipótesis, pero creo que vamos a asistir al nacimiento de un "multilateralismo imperial", al nacimiento de un imperio europeo, al nacimiento de uno o dos imperios asiáticos, al nacimiento de un imperio de América Latina, con todo lo que implica un problema multilateral. 